\title{
BINOCULAR WHITE FROM RED AND GREEN, AND THE THREE-COMPONENT THEORY*
}

\author{
BY \\ GORDON L. WALLS \\ School of Optometry, University of California, Berkeley, Calif.
}

RECENTLY Hurvich and Jameson (1951) have criticized certain experiments designed to show whether yellowness is synthesized from redness and greenness (as the three-component theory of colour vision holds), or is given by the activity of a separate (yellow-blue) receptor in accordance with the opponent-colours (Hering) theory and its derivatives.

These were experiments in which a red stimulus was supplied to one retina and a green one to the other. If the observer obtains a binocular yellow sensation, this could be taken to prove that its yellowness (hence, presumably, monocular yellowness also) is created centrally from the activities of redness receptors and greenness receptors. Hurvich and Jameson did not review the whole history of such haploscopic presentation of red and green stimuli, but singled out the particular experiment of Hecht (1928) with filtered lights, and its repetition with modern narrow-pass filters by Prentice (1948).

Quite properly, these experiments were considered to prove nothing, since in each case the red stimulus employed afforded a slightly yellowish-red sensation and the "green" stimulus was really a yellow-green one. There being a yellow aspect to the hue of each monocular colour, the presence of yellowness in the binocular experience would be in no way mysterious according to any theory of colour vision. What seemed, however, to call for explanation was the disappearance of the redness and the greenness-if these were not being integrated into yellowness.

Hurvich and Jameson speak of this disappearance as the result of a " central cancellation ", the mechanism of which, they consider, " constitutes a real problem ". The problem is real only if the redness and greenness do in fact disappear without having been used up in making yellowness. One may suspect that in the Hecht experiment there is not nearly enough total yellowness in the monocular sensations to account for the magnitude of the binocular yellowness; but to test this suspicion quantitatively would be very difficult to say the least. Easy and genuine proof of mutual cancellation of redness and greenness, as against their synthesis into yellowness, would however come from a situation in which red and green sensations, neither of which had any other hue-aspects, disappeared upon combination without the emergence of any yellowness whatever.

Hurvich and Jameson perceived this, and claim to have performed the crucial experiment. For each of the two observers (LMH, DAJ) a mixture of $\lambda 671 \mathrm{~m} \mu$ and $\lambda 440 \mathrm{~m}_{\mu}$ was devised which afforded a " pure " red sensation,

Received for publication October 23, 1951. 
and a third monochromatic light was chosen which gave a "pure" green sensation $-\lambda 498.1 \mathrm{~m}_{\mu}$ for DAJ, $\lambda 489.4 \mathrm{~m}_{\mu}$ for LMH. The authors used "pure" not in the colorimetric sense, nor (as is common) to describe the hue of any monochromatic light, nor to describe a stimulus yielding a fully saturated sensation, but to describe a colour-experience having in it only a single kind of huedness (redness, or greenness) together with the inescapable desaturative "whiteness". Their usage will be employed here to avoid confusion (although " unique" and " unitary" are established terms having the same significance).

When LMH and DAJ each viewed haploscopically the stimuli which satisfied them respectively as pure green and pure red, their binocular experience was either a reddish or greenish colour depending upon intensityratios; but it was never a yellow, and at one intensity-ratio it was " a neutral, hueless sensation", i.e., what is generally called white. They considered this result to be " in direct conflict with the ordinary assumptions of a threecomponent theory" although it is "predicted by traditional four-component theories, where red and green are assumed to be opponent or complementary colours ". They admitted, however, that possible modifications of the threecomponent theory would " enable it to account for the emergence of a white sensation from a mixture of pure red and pure green ". This is ambiguous, as it is not clear whether they are challenging the three-component theory to explain the result of a mixture of stimuli or that of a "mixture" of sensations. Haploscopic stimuli cannot be said to be undergoing " mixture " and to speak of whiteness as arising from a mixture of redness and greenness begs the question. It has first to be demonstrated that whiteness is ever " mixed " (synthesized) from huednesses of whatever number and kinds.

Hurvich and Jameson are emphatic in refraining from a choice between theories on the basis of their one surprising experiment. But others will make the choice, and the signs are already evident (New York Times, 1951). The authors themselves speak of a " mysterious, synthetic central emergence of the quality yellow"-which is the mode of expression of a critic, not an adherent, of the three-component theory.*

Let the validity of Hurvich and Jameson's crucial experiment be temporarily assumed. It appears to demonstrate that when monoccular sensations contain no hues but red and green the binocular sensation contains no yellowness because redness and greenness cannot synthesize yellowness, and also contains neither redness nor greenness because these have "cancelled" each other as if they were perfectly opponent qualities such as Hering contemplated. Haploscopic yellowness and blueness can also disappear with the emergence of only whiteness binocularly, as is well known; but, since yellow and blue are "complementary" under the threecomponent theory as well as being "opponents" under the six-component

\footnotetext{
* It seems strange that psychologists, of all people, should call the synthesis of one sensory quality from two others " mysterious", as if it were incredible and probably non-existent. They were psychologists (Alrutz, Bentley) who demonstrated long ago that dermal wetness is synthesized from coldness and pressure, and that burning hotness is synthesized from coldness and mild warmth.
} 
theory, Hurvich and Jameson did not even mention Hecht's execution of this latter experiment, let alone repeat it using " pure" stimuli.

Would, now, a binocular sensation of whiteness from haploscopic red and green stimuli "shake the three-colour theory" and "support the fourcomponent colour theory" ? Not at all. It needs to be remembered that any and every colour-vision theory so far proposed is purely ad hoc in that it is tailored to the facts of monocular colour vision. If binocular facts are found which appear to conflict with a given theory, they cannot be deemed to destroy it. If binocular facts are found which appear not to conflict with a particular theory, they cannot properly be considered to support it. The peculiarly binocular portions of the human visual apparatus are secondary impositions upon the monocular systems. For two reasons, they cannot legitimately be expected to possess, necessarily, counterparts of all monocular capacities; they are phylogenetically newer, and serve to supplement rather than to duplicate the potentialities of monocular vision; and, since haploscopic presentation of chromatically different stimuli does not occur in the natural environment of prescopic vertebrates, the essentially binocular apparatus need never have evolved any machinery for dealing with it.

This argument is not at all strong if whiteness is centrally synthetic, and if central binocular sensory "fusions" do take place in respect of visual attributes other than chromaticness. Several years ago, however, I concluded against the existence of genuine binocular physiological fusion of anything but chromaticness (Walls, 1948), and, at about that time, I began to teach a version of the three-component theory which denies the synthetic character of whiteness.

Newton is seldom if ever given proper credit for having understood that colour is subjective and not a physical property of lights and pigments. Despite this understanding, no sooner had he produced the prismatic spectrum than he committed the flagrant stimulus error that was later taken into the three-component hypothesis of Thomas Young.* Since a white light can be made by mixing coloured lights, almost everyone from Newton on down has supposed that a white sensation is mixed from coloured sensations. Seldom has any three-componentist spoken against this; but Southall (1924) did say that white may be the most fundamental and "elementary" of all visual sensations, and that he saw no reason to infer that the sensation of white is complex-composed, for example, of a sensation of yellow plus a sensation of blue.

In three-component thought, separate redness, greenness, and blueness receptors are conceived to arouse respective pro-sensational processes, which are blended to produce the experienced sensation. The traditional view holds that if a pro-sensation could stand alone the individual would experience a colour having a pure hue and some unimaginable degree of saturation. Pure yellowness results from the mergence of magnitudes of

\footnotetext{
* Historically, this was not the first but no better than the second (perhaps even the third) theory to explain colours as being comprised from three sensory components. In the much earlier three-component theory of Palmer (1777), whiteness was explained as due to the absence of a basis for huedness.
} 
redness and greenness which are, in some sense, "equal ". Whiteness is also synthetic, but requires all three pro-sensations to be aroused and to be " equal".

If whiteness were synthesized from three pro-sensational components, then in photopic adaptation, with his rods greatly desensitized, a protanope could not experience whiteness from a piece of white paper or from monochromatic light at the wave-length of his neutral point. Lacking the redness pro-sensation, he would see such stimuli as highly saturated blue-greens. A tetartanope, who lacks blueness receptors, would perceive whites and his two neutral-point wave-lengths as strong yellows. A congenital atypical achromate who was simultaneously protanopic and tetartanopic would see everything in rich green.

These people do not see white stimuli as coloured, but as white in the normal's sense of the word. This is more than merely to say, as the cautious do, that, e.g., a protanope calls his neutral-point light white only because it looks the same to him as a white light does, with both stimuli giving him a sensation of unknown and unknowable quality. These loss-dichromates and achromates, be it noted, have their perfectly normal scotopic (rod) whiteness to tell them what "white" means to the normal. If a white paper looked any different, qualitatively, to a colour-blind in photopia from what it did in scotopia, he would be able to say so. Very obviously, it does not.

This is the foremost of the reasons why I append, to the three-componen $B$ explanation of huedness, the excess hypothesis (of saturation). The excess hypothesis explains whiteness quite otherwise than by synthesis, makes the three-component theory workable, and makes a six-component theory unnecessary. It is the "further modification"-capable of explaining a binocular genesis of whiteness from haploscopic red and green stimuli (if this does indeed occur) - which Hurvich and Jameson have asked for. Further evidence for it, and for the three-component theory proper, is being given elsewhere (Walls and Mathews, 1952). According to the excess hypothesis:

(a) A pro-sensation which exceeds a finite magnitude of another pro-sensation introduces its specific huedness into the sensation.

(b) If two pro-sensations exceed a third, the huednesses of both appear in the sensation (excepting where yellowness is formed, accompanying an excess of redness or an excess of greenness, or standing alone).

(c) A pro-sensation which exceeds no other introduces only desaturative whiteness into the sensation, whether it stands alone, or is exceeded by one other pro-sensation, or by two.

In this view whiteness exists not by synthesis, but by default of any basis (in an imbalance of pro-sensations*) for huedness. Yellowness however. in its synthetic origin, remains a " special case".

\footnotetext{
* Willmer (1949) came close to a formulation of the excess hypothesis when, from his studies of central-foveal vision in certain rare deuteranopes, he was led to say: "Presumably, colour sensations must derive from differences in response between two or more pathways, and not as the result of the response along a single pathway when this cannot be compared with the response along another or other pathway
} (1) 
Returning now to the situation where whiteness has been claimed to result from haploscopic stimulation with pure red and green lights. What is the sensory situation via each eye singly? A " pure" sensation is being given because one pro-sensation is in excess and the other two are equal and hence find expression only as whiteness. In monocular vision, redness and greenness standing thus alone over whiteness, if equal to each other, would synthesize pure yellowness under the three-component theory. In haploscopic vision, however, equal redness and greenness pro-sensations need not necessarily synthesize anything at all under the excess hypothesis. They will each come into the sensation as whiteness-not through synthesis of the latter, nor because they "cancel", but simply because they are equalif the peculiarly binocular sub-perceptual apparatus has no provision for synthesizing yellowness from them. I have already asked, "why should it ?"; and I have already said that I can see no reason why any theory of the monocular colour-vision mechanism should be expected to stand ready to account for anything and everything that may be found to happen, or not to happen, in binocular vision. Pure redness and greenness could well behave like "complementaries" in normal binocular vision just as they do in the monocular vision of a tetartanope. For that matter, so could redness and blueness, or blueness and greenness.

The synthetic origin of monocular yellowness has been demonstrated in no less than three independent researches, where means were found of activating the redness and greenness receptors separately with monochromatic " pure" yellow light (Göthlin, 1943; Otero, Plaza, and Casero, 1948; Stiles, 1949). No bolstering hypothesis is necessary to explain such dissectibility of yellowness, for a prediction of this is tacit in the traditional three-component theory. Not tacit, however, is a consideration which has always seemed embarrassing, but becomes less so in the light of the excess hypothesis (and the complete desaturation of binocular red-plus-green, if this be a fact).

This is the extremely low saturation of even monochromatic yellow. It is generally taught that the blueness receptors have no responsivity whatever at wave-lengths as long as that of the locus of pure yellow. Yet, yellow is by far the least saturated colour in the spectrum. It is as if when redness and greenness do synthesize-even in monocular vision-as much or more whiteness is "formed" (without need of any blueness), as yellowness. This has led to at least three independent postulations that one pro-sensation may desaturate another (Hamilton and Freeman, 1932; Hecht, 1931, 1934; Rawdon-Smith, 1938) - at any rate, where redness and greenness happen to be the two pro-sensations concerned. Yellowness is perhaps then a special case not only because it is qualitatively unlike its two components but because some of it may be generated when only two pro-sensations are present and equal, where the excess hypothesis calls for only whiteness to result. If there is no blueness activity at the yellow locus of the spectrum, 
which is not proved (Walls and Mathews, 1952), then monocular yellowness from redness and greenness is much more of a puzzle than is binocular whiteness from haploscopic redness and greenness.

But, did Hurvich and Jameson obtain binocular whiteness from pure redness and pure greenness? It is hard to see how they possibly could have, when one considers what their stimuli were. Each of the two observersin the particular state of adaptation upon which they standardized-obtained what was deemed pure red from a mixture of $\lambda 671 \mathrm{~m}_{\mu}$ and $\lambda 440 \mathrm{~m}_{\mu}$. DAJ chose $\lambda 498.1 \mathrm{~m} \mu$ as providing a pure green sensation, while for this LMH required $\lambda 489.4 \mathrm{~m}_{\mu}$.

When the red stimulus was viewed with one eye and the green one with the other, each observer experienced a " neutral, hueless" sensation. If this is to be considered to prove or disprove anything, it would have to be true that if the very same stimuli at the very same intensities had been mixed on one retina, a hued-and specifically, a yellow-sensation would have resulted. Now the stimuli which afforded binocular " neutral " sensations were:

IFor DAJ : $12.8 \mathrm{~mL} 671+2.5 \mathrm{~mL} 440$ and $0.55 \mathrm{~mL} 498.1$

For LMH : $12.8 \mathrm{~mL} 671+3.0 \mathrm{~mL} 440$ and $0.36 \mathrm{~mL} 489.4$

The first thing that strikes one as strange here is the enormous photometric discrepancy between the left- and right-eyed stimuli. Complementation in monocular vision always requires a greater intensity of the less-saturated stimulus, and the rules of haploscopic complementation are not supposed tog be markedly different in this regard.

The next thing to consider is what chromaticity would have resulted if the red and green stimuli of each observer had been mixed without alteration and presented to one retina. DAJ's monocular stimulus would then have been one which, on the International Commission on Illumination (Commission Internationale d'Eclairage) chromaticity diagram, plots at $x=0.61598, y=$ 0.23502 . This is no yellow, but a purple having a dominant wave-length of $494.1 \mathrm{~cm} \mu$ and an excitation purity of 89.8 per cent., with reference to a generally-accepted standard white (C.I.E. Illuminant C). LMH's monocular stimulus would plot at $x=0.61147, y=0.22056$, which is again a purple, with a dominant wave-length of $494.8 \mathrm{~cm} \mu$ and a purity of 94.9 per cent. If two moieties of a monocular purple stimulus, presented haploscopically, fail to arouse a yellow sensation, this should not surprise anyone.

In correspondence with Dr. Hurvich, I raised the question of what the monocular visual result of their combination of stimuli would have been. It appears that Hurvich and Jameson did view the combined stimuli monocularly, but in their paper "omitted any reference to the monocular results so as not to be sidetracked . . . from (their) major point " Hurvich (1951). The monocular result was, however, most revealing; for: "with regard to the question of the difference between monocular and binocular mixture results, qualitatively they are identical " (Ibid.).

This means that Hurvich and Jameson obtained their binocular whiteness- 
sensation from stimuli which, in monocular vision, were complementary since in a particular (the same ?) intensity-ratio they afforded a white sensation there also. They could not have been made to give a yellow sensation monocularly. The fact that they did not do so binocularly ceases to have anything to do with the relative merits of the three-component theory and other theories of colour vision.

No-one has ever found pure red and pure green photopic stimuli to be complementary, or to give anything but yellow-green, yellow, or orange in near-equal intensity ratios. But then, no-one has ever found the "pure" stimuli to be located in the spectrum where Hurvich and Jameson found theirs. For example, their respective pure greens were $\lambda 489.4 \mathrm{~m}_{\mu}$ and $\lambda 498.1 \mathrm{~m}_{\mu}$. These values " straddle " Hering's Urgrün stimulus- $\lambda 495.0 \mathrm{~m}_{\mu}$ -which is generally regarded not as a green but as a "pure" blue-green, and was chosen by Hering to be a perfect complement of his Urrot stimulus (as demanded by his own theory). Hurvich and Jameson tabulate the " pure green "wave-lengths they were able to find in 50 years' literature, but without noting that the mean value for the subjects tabulated is $\lambda 512.1 \mathrm{~m}_{\mu}$, quite distant from their own two individual values.

LMH found pure yellow at $\lambda 588.9 \mathrm{~m}_{\mu}$ whereas for DAJ it lay at $\lambda 579.5 \mathrm{~m}_{\mu}$. To account for a displacement of pure yellow to a wave-length even as long as $584 \mathrm{~m}_{\mu}$, Judd had to postulate an abnormally heavy macular pigmentation and an abnormally reddish colour of the macular pigment, when he assisted Sloan and Wollach (1948) to interpret their subject " D. D.", who had one deuteranopic eye and one mildly deuteranomalous eye (Walls and Mathews, 1952). The expected spectral locations of pure yellow and pure blue are at $\lambda 575 \mathrm{~m}_{\mu}$ and $\lambda 470 \mathrm{~m}_{\mu}$ (Judd, 1948). Even $\lambda 584 \mathrm{~m}_{\mu}$ is a reddish yellow in normal colour vision (Sloan and Wollach, 1948), and the sodium lines are generally called orangeish by expert colourists $-\lambda 600 \mathrm{~m}_{\mu}$ being central orange.

The differences between DAJ and LMH are such that it looks unlikely that they can both have normal colour vision. LMH's pure-hue locations are reminiscent of those for the slightly anomalous "normal" eyes of two unilateral deuteranopes and one unilateral extreme deuteranomal in the literature (Sloan and Wollach, 1948; von Hippel, 1880; Reichert, 1916; Walls and Mathews, 1952). Hurvich (1951) states, however, that LMH exhibits no degree of deuteranomaly on standard colour-vision tests.

The differences between the two observers thus remain unexplained. The differences they show in common, from reasonable expectations, also demand explanation. Each obtained a white sensation, binocularly and monocularly, from stimuli which "should" have appeared coloured (though with the hue of purple, not yellow in any case). One can only suppose that their state of adaptation accounted for this, and perhaps accounts for the spectral locations at which they found their pure hues.

Hurvich and Jameson (1951) describe their preparation for viewing any 
of their stimuli as a 10-minute stay in darkness which, they consider, put them in "a neutral state of adaptation". Ten minutes is long enough to produce complete dark-adaptation of the cones of the average individual. Following such preparation, Hurvich and Jameson proceeded to view stimuli at photopic levels, as intense as 15.8 millilamberts. It is easy to $\stackrel{\oplus}{\oplus}$ imagine that the huedness of the sensation in their crucial experiment was simply " glared out" by their excessive sensitivity, making the sensation an acceptable "white".*

It should be clear that Hurvich and Jameson's must not be allowed to be the last repetition of the Hecht experiment. Their basic idea of viewing haploscopic "pure" red and green stimuli was splendid. Such stimuli should however be devised for an indisputably colour-normal observer under $\overrightarrow{\mathscr{\omega}}$ the photopic conditions which are optimal for colour vision. His 응. preliminary adaptation should be to an extensive Munsell N 5/ surface $\dot{\omega}$ illuminated with a true physiological white light (probably $7500^{\circ} \mathrm{K} ; \stackrel{\circ}{i}$ Walls and Mathews, 1952), at the luminance level of the chromatic stimuli os which he is later to view. Each of the chromatic stimuli should be presented $\frac{}{\square}$ in a bipartite field containing a standard white also.

On the basis of such a pursuit of Hurvich and Jameson's excellent idea, it should at last be determinable whether dextro-ocular redness and sinistroocular greenness, each standing alone in its eye's sensation except for desaturative whiteness, synthesize binocular yellowness or disappear. If $\vec{\bullet}$ they disappear, it will be time enough to spend more words in wondering whp

"LMH and DAJ had only a memory-standard of " neutrality" in their experiment. How dangerous this is, seen whenever a dichromate is allowed to determine his neutral-point wave-length on a monochromator-first without, and then with, a white comparison field (Walls and Mathews, 1952).

\section{REFERENCES}

Göthlin, G. F. (1943). "The Fundamental Colour Sensations in Man's Colour Sense" Almqvist-Wiksells, Stockholm.

Hamilton W. F., and Freeman, E. (1932). Science, 75, 292.

Hecht, S. (1928). Proc. nat. Acad. Sci. (Wash.), 14, 237. (1931). J. opt. Soc. Amer., 21, 615.

(1934). In "A Handbook of General Experimental Psychology", ed. C. Murchison. Clark University Press, Worcester, Mass.

von Hippel, A. (1880). v. Graefes Arch. Ophthal., 26, Part 2, 176.

Hurvich, L. M., and Jameson, D. (1951). Science, 114, 199.

Personal communication, Sept. 7, 1951.

JUDD, D. B. (1948). J. Res. Nat. Bur. Stand., 41, 247.

New York Times, Sept. 2, 1951. Section 4, p. 7, article signed R.K.P.

Otero, J. M., Plasa, L., and Casero, L. (1948). An. Soc. Esp. Fis. Quín., Ser. A. 44, 16.

PAlmer, G. (1777). " Theory of Colours and Vision", p. 46. Leacroft, London.

Prentice, W. C. H. (1948). J. exp. Psychol., 38, 284.

Rawdon-Smith, A. F. (1938). "Theories of Sensation". University Press, Cambridge.

REICHERT, F. (1916). "Ueber eiseitige Farbensinn-Anomalien". Blech, Mulheim a. d. Ruhr

Sloan, L. L., and Wollach, L. (1948). J. opt. Soc. Amer., 38, 502.

Southall, J. P. C. (1924). In "Helmholtz's Treatise on Physiological Optics", ed. J. P. C. Southall, vol. 2, p. 61, footnote. Optical Society of America, New York.

Stiles, W. S. (1949). Docum. Ophthal., 3,138.

WALlS, G. L. (1948). Optical J. Rev. Optom., 85, 33.

and Mathews, R. W. (1952). "New Means of Studying Color Blindness and Normal Foveal Color Vision. With some Results, and their Genetical Implications ". Univ. Calif. Publ. Psychol., 7, 1.

Willmer, E. N. (1949). J. Physiol., Lond., 110, 437. 